S. M. SORIA-CASTRO, B. LEBEAU, M. CORMIER, S. NEUNLIST, T. J. DAOU*, J.-P. GODDARD* (UNIVERSITÉ DE HAUTE-ALSACE, MULHOUSE, AND UNIVERSITÉ DE STRASBOURG,

\title{
FRANCE)
}

Organic/Inorganic Heterogeneous Silica-Based Photoredox Catalyst for Aza-Henry Reactions

Eur. J. Org. Chem. 2020, 1572-1578.

\section{SAB-15-Supported Rose Bengal as a Heterogeneous Photoredox Catalyst}

SAB-15 = ordered mesoporous silica

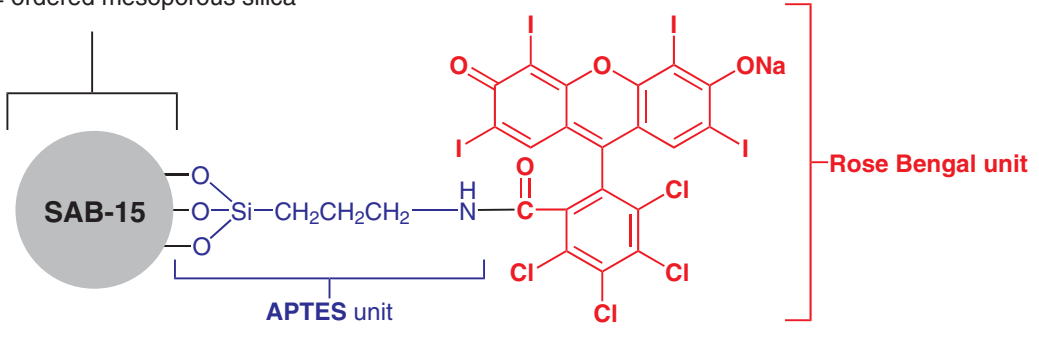

SAB-15-APTES-RB
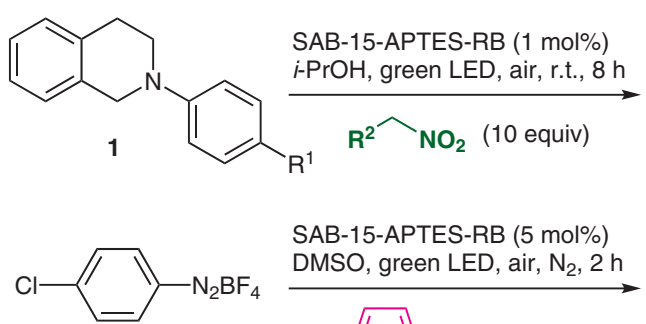

3
SAB-15-APTES-RB (5 mol\%) (10 equiv) DMSO, green LED, air, $\mathrm{N}_{2}, 2 \mathrm{~h}$
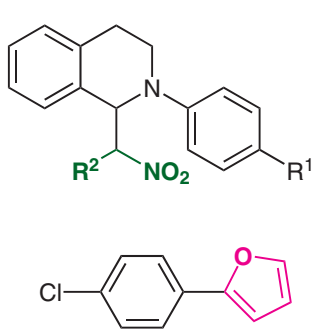

2a: $R^{1}=H, R^{2}=H \quad: 91 \%$ yield 2b: $R^{1}=M e, R^{2}=H \quad: 82 \%$ yield 2c: $R^{1}=$ OMe, $R^{2}=H: 90 \%$ yield 2d: $R^{1}=F, R^{2}=H \quad: 92 \%$ yield 2e: $R^{1}=H, R^{2}=M e: 87 \%$ yield 2f : $R^{1}=H, R^{2}=E t \quad: 76 \%$ yield

\section{3: $77 \%$ yield}

control experiments with homogeneous RB: $70 \%$ yield

\section{Category}

Polymer-Supported Synthesis

\section{Key words}

photoredox reaction

aza-Henry reaction

mesoporous silica

rose bengal
Significance: A series of solid-supported dye composites consisting a rose bengal (RB) unit covalently linked to inorganic porous supports (e.g., silica or zeolites) were prepared for use as heterogeneous photoredox catalysts. An ordered mesoporous silica SAB-15-supported RB tethered to a 3-aminopropylsilane moiety (SAB-15-APTES$\mathrm{RB})$ catalyzed the aza-Henry reaction under green LED irradiation. For example, tetrahydroisoquinoline 1 a reacted with nitromethane in the presence of $1 \mathrm{~mol} \%$ of SAB-15-APTES-RB at room temperature under LED irradiation to give the aza-Henry adduct $2 a$ in $91 \%$ yield. SAB-15-APTES-RB was also effective for reductive coupling of the aryl diazonium compound $\mathbf{3}$ with furan, showing a catalytic performance that was comparable to that of its homogeneous counterpart carried out with RB.
Comment: A robust and readily recyclable RBbased photocatalyst for organic synthesis has not been well studied so far, although a similar mesoporous silica-supported RB has been developed as a photosensitizer (C. Mendoza et al. ChemPhotoChem 2018, 2, 890). SAB-15-APTES-RB was characterized by means of IR, UV/Vis, ${ }^{13} \mathrm{C}$, and ${ }^{29} \mathrm{Si}$ NMR analyses. In the reaction of 1 a with nitromethane, SAB-15APTES-RB was recovered and reused for a total of eight runs without significant loss of its catalytic activity, though a slight decrease of activity was observed in the ninth run or later. Molecular oxygen served as the sole oxidant for the aza-Henry reaction, which did not proceed in darkness under otherwise similar conditions. 